\title{
ETHANOLAMINE PHOSPHATE EXCRETION IN A FAMILY WITH HYPOPHOSPHATASIA
}

\author{
BY \\ R. A. GOYER* \\ From the Medical Unit, University College Hospital Medical School, London
}

(RECEIVED FOR PUBLICATION OCTOBER 17, 1962)

\begin{abstract}
Hypophosphatasia is an inherited disorder of bone, which is thought to be transmitted by a recessive gene. The homozygous form of the disease presents with a well-defined clinical picture and two biochemical abnormalities: lowered serum alkaline phosphatase and excessive urinary excretion of ethanolamine phosphate (EAP). Heterozygous carriers are usually not manifest clinically, but it has been suggested that they may be recognized biochemically. Both serum alkaline phosphatase and urinary EAP excretion have been studied for this purpose.

Rathbun, MacDonald, Robinson and Wanklin (1961) studied changes in serum alkaline phosphatase in 30 relatives of two sibs with hypophosphatasia. Of the relatives, $15(50 \%)$ had serum alkaline phosphatase levels below 2.0 Bodansky units, which was significantly lower than the mean of a comparable group of normal people. About $15 \%$ of the normal control group, however, were also below this value. This considerable overlap as well as the great variation in methods of measurement employed in different laboratories greatly reduces the usefulness of this test for the recognition of heterozygotes.
\end{abstract}

Paper chromatography was used by Harris and Robson (1959) to study the urinary excretion of EAP in 381 relatives of 16 cases of hypophosphatasia. This method suffers in this instance from lack of sensitivity, and they were only able to demonstrate EAP excretion in $58 \%$ of the expected carriers.

The purpose of this paper is to describe the use of ion-exchange chromatography for the accurate measurement of EAP excretion in the immediate members of a family in which two sibs have hypophosphatasia. The clinical aspects of these two

\footnotetext{
* Present address: St Louis School of Medicine, Missouri.
}

cases have been previously described in detail (Bethune and Dent, 1960).

\section{Methods}

Urine from nine members of the family under study and eight normal young adults was analysed. Early morning samples were collected after an overnight fast, preserved with a few crystals of thymol and stored in a refrigerator $\left(4^{\circ} \mathrm{C}\right.$. $)$.

Total nitrogen content of the urine samples was measured by a micro-Kjeldahl procedure (Beet, 1955).

Two-dimensional amino acid paper chromatography was performed according to the method of Dent (1948).

Plasma alkaline phosphatase was determined by a slight modification of the method of King and Wootton (1951) described by Dent and Harper (1962). Determinations were performed on heparinized plasma in duplicate. All results are expressed in King-Armstrong (K.A.) units.

Ion-exchange column chromatography was performed according to the method of Moore and Stein (1954a) employing a $0.9 \mathrm{~cm} . \times 150 \mathrm{~cm}$. column of Dowex $50 \times 5$ cation exchange resin in the sodium form. An amount of urine equivalent to $40 \mathrm{mg}$. of total nitrogen was applied to the column. If this exceeded $5 \mathrm{ml}$., the urine was concentrated by vacuum distillation. Elution of amino acids was accomplished with $0 \cdot 2 \mathrm{~N}$ sodium citrate buffer, $p \mathrm{H} 2 \cdot 2$. Fractions $(2 \mathrm{ml}$.) were collected with a drop-counting collector and analysed by the photometric ninhydrin method of Moore and Stein (1954b). Since EAP and taurine are the first two amino acids to emerge from the column, the procedure was stopped when the next peak due to urea began to appear.

\section{Results}

Fig. 1 shows examples of chromatograms obtained by ion-exchange chromatography. Chromatogram $A$ is an analysis of a standard solution containing $1 \mu \mathrm{mol}$. of EAP and taurine. Recovery was 1.05 and $1.02 \mu \mathrm{mol}$. respectively. No ninhydrin-reacting substance was found in the region of EAP in urines from most of the normal subjects. In two, however, 


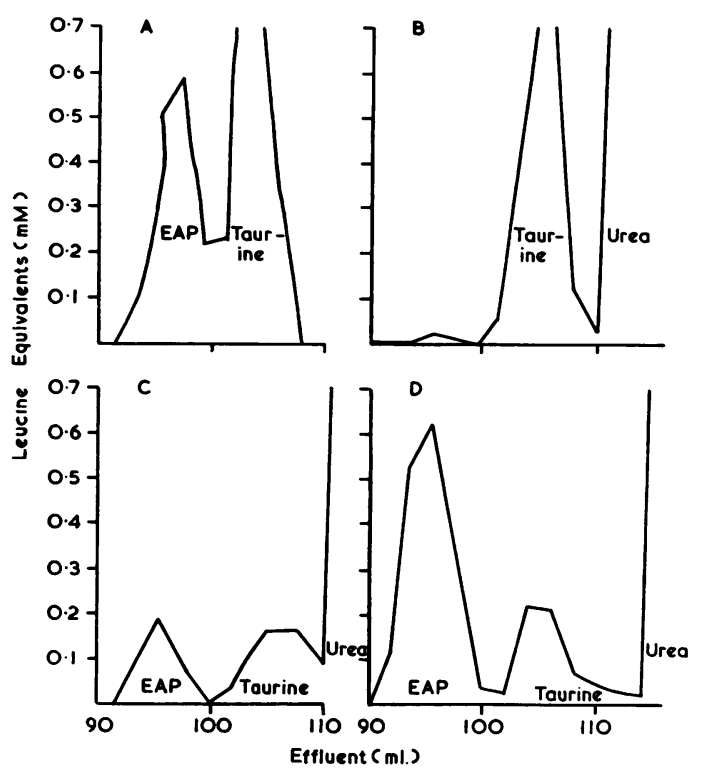

FIG. 1.-Chromatograms of, (A) standard solution containing ethanolamine phosphate and taurine, (B) urine from homozygous normal subject, (C) urine from mother (No. 1) of sibs with hypophosphatasia, (D) urine from sib (No. 4) with hypophosphatasia. $\mathbf{E A P}=$ ethanolamine phosphate.

there were barely detectable amounts measured as 0.3 and $0.5 \mathrm{mg}$. of EAP per g. N. One of these is depicted in chromatogram $\mathbf{B}$. The other differed slightly in position from the usual EAP peak and it might be questioned whether this substance is actually EAP. Exact identification has not been attempted but would be technically difficult because so little is present. Small amounts of EAP may be expected to be present in urine, since it is a normal metabolite and does have a high rate of renal clearance (Cusworth and Dent, 1960).

The analysis of urine from the mother of the sibs with hypophosphatasia is shown in chromatogram C. The ethanolamine phosphate peak is intermediate in size between the slight deflection noted in urine from a normal person (chromatogram B) and the large amount excreted by one of the persons with hypophosphatasia (chromatogram D).

The family pedigree with biochemical findings is depicted in Fig. 2. The two sibs with hypophosphatasia excreted 14.8 and $10.8 \mathrm{mg}$. of EAP per $\mathrm{g}$. urinary $\mathrm{N}$, respectively. This amount is equivalent to the 150 to $200 \mathrm{mg}$. per day measured previously by Cusworth and Dent (1960) in one of these sibs (No. 5) and is in the range (100-200 mg.) said by Harris and Robson (1959) to be characteristic of persons with hypophosphatasia. Four other members of the family excrete from 1.1 to $4.7 \mathrm{mg}$. of EAP per g. urinary $\mathrm{N}$ or about 10 to $50 \%$ of that excreted by the two homozygotes. Since these people excrete more EAP than that found in the urine of normal subjects they are thought to be heterozygous carriers of the abnormal gene. Both parents and a daughter of one of the sibs with hypophosphatasia are included in this group. Only two of the heterozygotes excrete enough EAP to be detected by the routinely employed method of paper chromatography. One member of the family (No. 9), the son of a homozygous normal subject excreted a slight amount $(0.7 \mathrm{mg}$. per $\mathrm{g}$. urinary $\mathrm{N})$ of a substance detected in the region of EAP. This

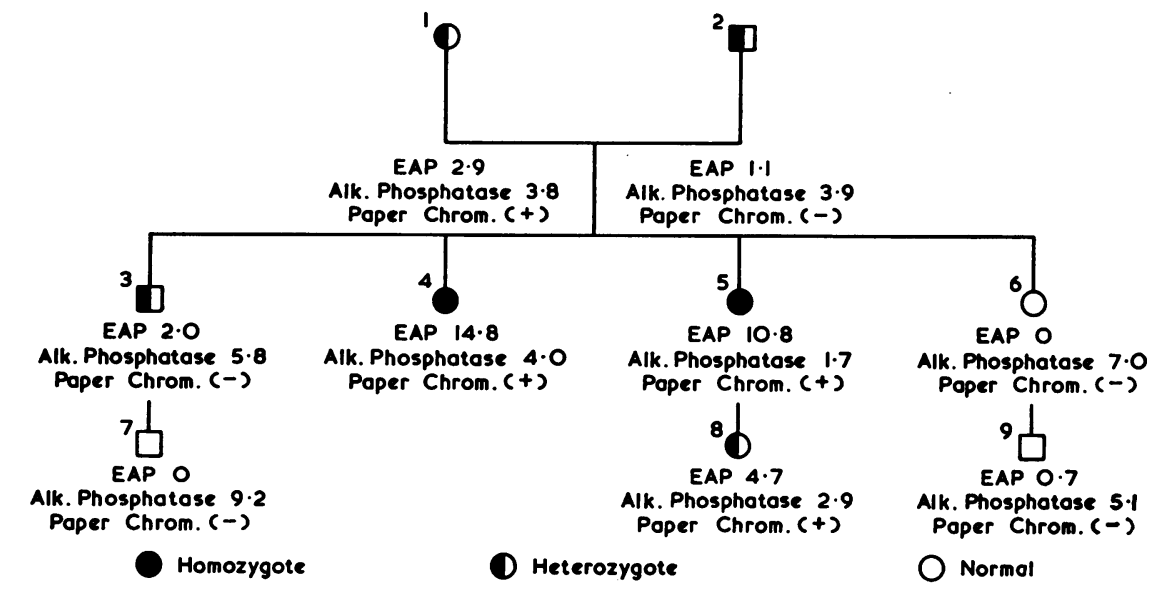

FIG. 2.-Family pedigree with biochemical findings. EAP $=$ mg. per g. N; alkaline phosphatase is given in King-Armstrong units; paper chrom. is paper chromatography. 
amount is similar to the previously discussed finding in the urine of two members of the normal control group.

\section{Discussion}

Ion-exchange chromatography provides an accurate and sensitive means of measuring urinary EAP excretion. Its use in the study of this particular family has resulted in the recognition of three groups, those homozygous for hypophosphatasia, heterozygous carriers of the abnormal gene and homozygous normal subjects. The two sibs with hypophosphatasia excreted at least $50 \%$ more EAP than any of the heterozygotes. The difference in EAP excretion between some of the heterozygotes and an occasional normal homozygote, however, is much less and in a larger study may result in some overlap. Nevertheless, this method of quantitation seems far more specific than the methods used up to now. As it requires only the first $100 \mathrm{ml}$. of a Moore and Stein analysis, the method is not too tedious.

Whether the same range of values for the three groups determined in this family will be found in other families is of interest. The studies of Currarino, Neuhauser, Reyersbach and Sobel (1957) and of Harris and Robson (1959) suggest the possible occurrence of more than one main gene for hypophosphatasia as well as different normal isoalleles in combination with the abnormal allele, which results in variation among the heterozygotes. Accumulation of values for EAP excretion in different families may contribute to our knowledge of the more subtle genetic aspects of this disease.

\section{Summary}

EAP excretion was measured by ion-exchange chromatography in a family in which two members have hypophosphatasia. Three groups were disdistinguished, those homozygous for hypophosphatasia, heterozygous carriers of the abnormal gene and homozygous normals.

I wish to thank Professor C. E. Dent for advice and encouragement and Dr. D. C. Cusworth for advice on ion-exchange chromatography. Phosphatase determinations were done by the Metabolic Ward Laboratory.

\section{REFERENCES}

Beet, A. E. (1955). Potassium permanganate in the Kjeldahl method for the determination of nitrogen in organic substances. Nature (Lond.), 175, 513.

Bethune, J. E and Dent, C. E. (1960). Hypophosphatasia in the adult. Amer. J. Med., 28, 615 .

Currarino, G., Neuhauser, E. B. D., Reyersbach, G. C. and Sobel, E. H. (1957). Hypophosphatasia. Amer. J. Roentgenol., 78, 392.

Cusworth, D. C. and Dent, C. E. (1960). Renal clearances of amino acids in normal adults and in patients with aminoaciduria. Biochem. J., 74, 550 .

Dent, C. E. (1948). A study of the behavior of some sixty aminoacids and other ninhydrin-reacting substances on phenol'collidine' filter-paper chromatograms with notes as to the occurrence of some of them in biological fluids. ibid., 43, 169. and Harper, C. M. (1962). Plasma-alkaline-phosphatase in normal adults and in patients with primary hyperparathyroidism. Lancet, 1, 559 .

Harris, H. and Robson, E. B. (1959). A genetical study of ethanolamine phosphate excretion in hypophosphatasia. Ann. hum. Genet., 23, 421.

King, E. J. and Wootton, I. D. P. (1951). Microanalysis in Medical Biochemistry, 3rd ed. Churchill, London.

Moore, S. and Stein, W. H. (1954a). Procedures for the chromatographic determination of amino acids on four per cent crossgraphic determination of amino acids on four per cent cros
linked sulfonated polystyrene resins. J. biol. Chem., 211, 893. linked sulfonated polystyrene resins. J. biol. Chem., 211, 893. metric determination of amino acids and related compounds. ibid., 211, 907.

Rathbun, J. C., MacDonald, J. W., Robinson, H. M. C. and Wanklin, J. M. (1961). Hypophosphatasia: A genetic study. Arch. Dis. Childh., 36, 540. 